
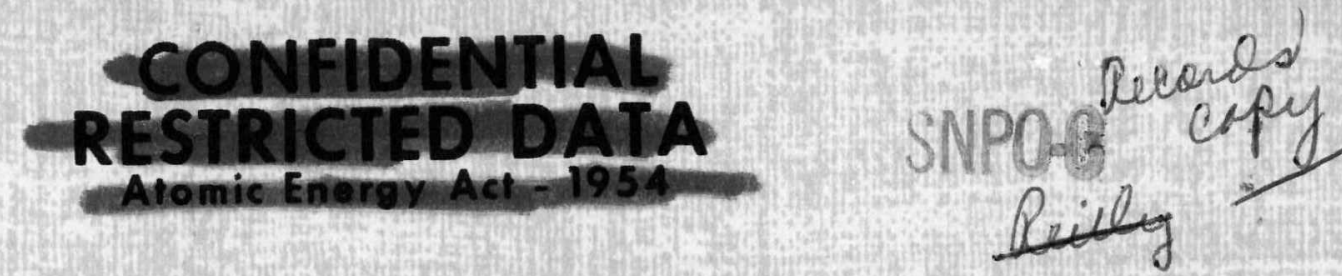

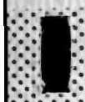

WANL-TME-823

September 1964

(Title Unclassified)

EML-16 WR No. 41:41:04-36W

\title{
w
}

\section{MASTER \\ CORE TIE ROD SIMULATING EXTREME \\ OPERATING CONDITIONS}




\section{DISCLAIMER}

This report was prepared as an account of work sponsored by an agency of the United States Government. Neither the United States Government nor any agency Thereof, nor any of their employees, makes any warranty, express or implied, or assumes any legal liability or responsibility for the accuracy, completeness, or usefulness of any information, apparatus, product, or process disclosed, or represents that its use would not infringe privately owned rights. Reference herein to any specific commercial product, process, or service by trade name, trademark, manufacturer, or otherwise does not necessarily constitute or imply its endorsement, recommendation, or favoring by the United States Government or any agency thereof. The views and opinions of authors expressed herein do not necessarily state or reflect those of the United States Government or any agency thereof. 


\section{DISCLAIMER}

Portions of this document may be illegible in electronic image products. Images are produced from the best available original document. 


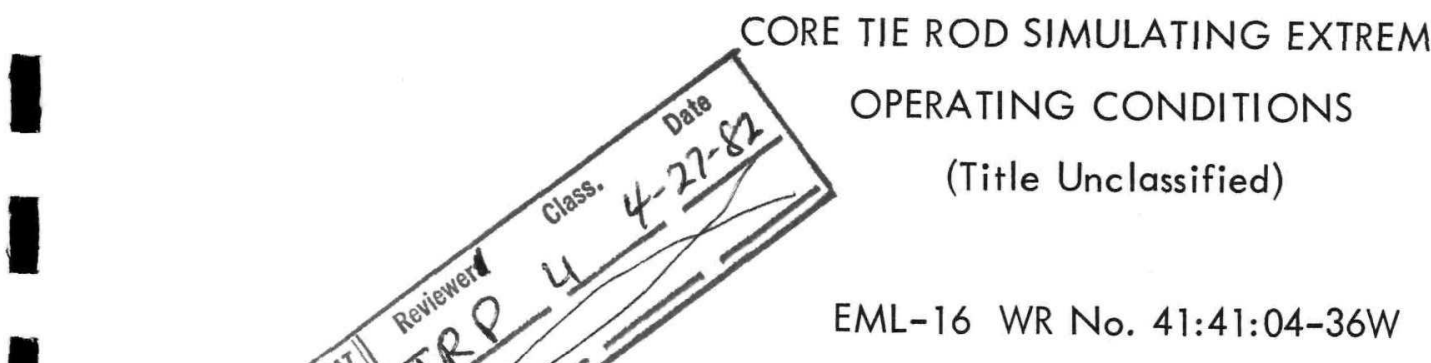

Westinghouse Electric Corporation Astronuclear Laboratory

P. O. Box 10864

Pittsburgh, Pennsylvania 15236

PREPARED BY:

F. M. Kotulak

T. F. Hengstenberg

Engineering Mechanics

APPROVED BY:

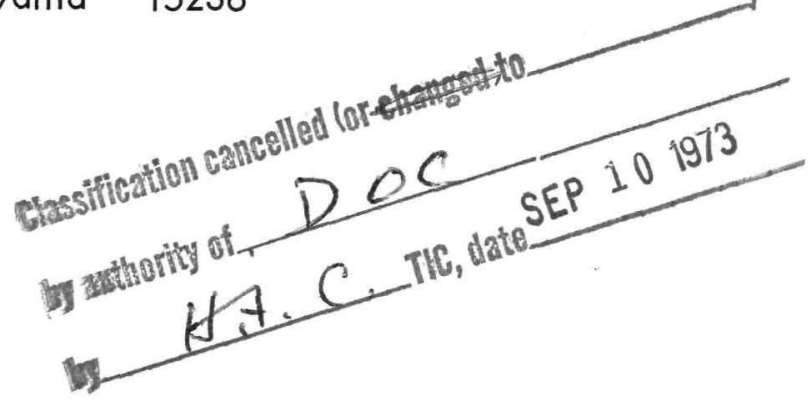

W.7. hieler

D. F. Miller, Supervisor

Reagtor Assembly \& Dynamics Experiments<smiles>C1=CCC2CCCCC(C1)C21CCCCC1</smiles>

N. J. Rowan, Manager

Engineering Mechanics

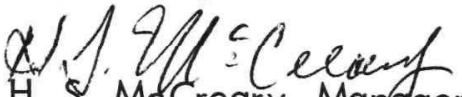

H. S. MCCreary, Mandger

Experimental Engineering

Wh. R

W. G. Roman, Manager

Reactor Engineering, NERVA Project

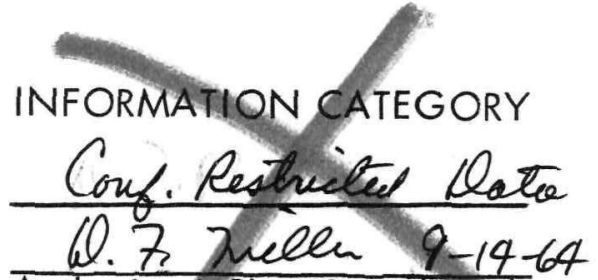

Authorized Classifier (Date) 


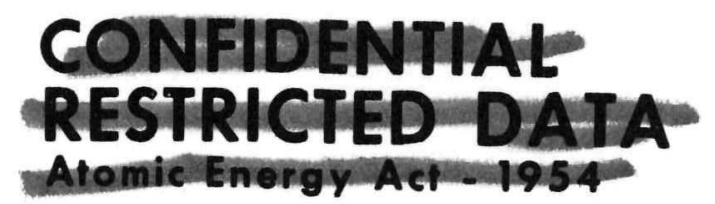

Title

$\underline{\text { Page }}$

1. Summary

1

2. Introduction

3. Purpose

4. Objectives

5. Conclusions

3

6. Recommendations

7. Test Specimen

8. Test Equipment

9. Results

10. Test Procedure 


\section{INTRODUCTION}

2.1 The wide extremes of temperature experienced in the operation of the NERVA reactor, especially during startup and shutdown, will, due to thermal growth and the variable coefficients of expansion in the different material used, induce severe stresses in the components. There is concern that bending stresses imposed on the already highly stressed tie rod could induce premature failure in the tie rod, which would then adversely affect successful reactor operation. Tests were conducted to substantiate analytical work and prove that the tie rods will perform satisfactorily under the extreme load conditions encountered during reactor startup and shutdown.

2.2 This test was considered a prerequisite for the NRX-A test and the report satisfies all the objectives of EML-16 Test Specifications.

3. PURPOSE

3.1 The purpose of this test is to determine the stress distribution in the core tie rod at specified conditions of displacement and axial load, and the structural integrity of the tie rod subjected to extreme (simulated) operating conditions for a limited number of cycles.

3.2 To determine the fatigue life of the tie rod when cycled laterally over the maximum range.

\section{OBJECTIVES}

4.1 Determine the stress distribution in the core tie rod due to specified displacement and axial load.

4.2 Determine if the tie rod will fail during a specified number of axial load and laterally displaced cycles at cryogenic temperature. 


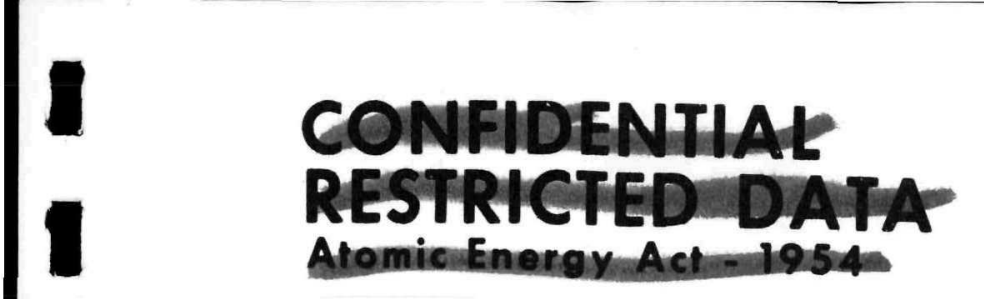

for 38,000 cycles in cryogenic temperature $\left(-320^{\circ} \mathrm{F}\right)$ before failure. Failure occurred approximately 5-1/8 in. from the threaded end where the tie rod enters the split bushing. There was considerable evidence of fretting which creates a strength reduction factor and thus contributing to early crack initiation.

5.4 Interference between tie rod and preload spring occurs under the maximum offset condition. We are of the opinion that this condition results from loose fitting tolerances in the attachment hardware seat and centering hub of thesplit bushing. This condition occurs at a point where the bending stress is very low.

5.5 Fretting between the tie rod and the split bushing creates a strength reduction factor severe enough to cause the tie rod to fail under cyclic loading in the bushing where the measured strain is approximately 30 per cent of the strain value at the thread fillet.

\section{RECOMMEDNATIONS}

6.1 As noted in the results, wear occurred on the tie rod due to the friction of the rod in contact with the preload spring when the tie rod was cycled at $0.200 \mathrm{in}$. offset. The factors responsible for this condition to exist apparently were the very loose fitting tolerances of the spring in the attachment hardware (bolt, Part No.977D774) and the centering (split) bushing, Part No.963B343. It is suggested that these components could be redesigned to provide a closer fit. This would involve increasing the diameter of the split bushing (spring) end, and decreasing the diameter of the bolt (spring) seat.

6.2 If long periods of vibration are anticipated the problem of fretting corrosion of Inconel 750 in contact with the aluminum bushing material may become critical. The fatigue strength may be reduced by a factor of 3 or more. 


\section{TEST SPECIMENS AND COMPONENTS}

7.1 Two core tie rods (Part No. 944C732H01, Serial Nos. V305 and V386) of Inconel 750 material, were instrumented with strain gages, placed back to back in the same plane, as shown in Figures 3 and 6 for the determination of stress distribution in the core tie rod at specified lateral displacements and axial loads. Budd Strain Gage, Type C6 1x1-M50A, Lot No. A8-FBB-2 were cemented to the rod at the locations shown in Figure 3. A third tie rod (V326) was instrumented with two gages for calibration purposes.

7.1.1 Included in the test setup was support plate attachment hardware including; the centering bushing, Part No. 944C407H02; split bushing, Part No. 963B343; tie rod holder, Part No. 977D774; tie rod nut, Part No. 963B338; preload spring, Part No.963B484, and the tie rod holder nut, Part No. 945C463. It was necessary to modify the tie rod holder as shown in Figure 8 to permit routing of strain gage lead wiring. All these parts were used to duplicate reactor assembly and loading conditions.

\section{TEST EQUIPMENT}

8.1 The test specimen used to determine the stress distribution in the tie rod, as shown in Figures 1 and 2 consisted of a test rig (ref. Drawing NT 700971) used in conjunction with the Wiedemann Testing Machine. The test rig simulating the core support plate (shown in cross section in Figure 7) was designed to provide offset (bending of 0 to $0.250 \mathrm{in}$. in the tie rod with a simultaneous axial load provided by Wiedemann 
Testing Machine. The offset was induced at the split bushing (point) A of Figure 7) which is approximately $5-1 / 8 \mathrm{in}$. from the tie rod threaded end. Displacement was accurately controlled with the aid of a dimensional gage mounted on the crossarm of the tensile machine (Figure 4). Strain gage readout equipment used for this test is shown in Figure 1.

8.2 The offset cycling could be accomplished by two different means: (1) by hand if the cycling was to be in one plane, and (2) rotation of the housing of the test fixture, thus subjecting the entire circumference of the tie rod to the maximum cyclic bending stress. The rotation of the housing sets up a wobbling action of constant amplitude See Figure 7. Liquid nitrogen was control fed from a dewar into the fixture.

\section{RESULTS}

9.1 Maximum stress, in a tie rod subjected to offset bending with axial load, as determined by the stresscoat crack pattern and strain gage readout, occurred at the base of the thread fillet $(5 / 8$ to $3 / 4 \mathrm{in}$. from the end) and at the split bushing (approximately 5-1/8 in. from the end). Figure 4 illustrates the strain values at various conditions at axial load and offset. Yielding occurred in the tie rod at $820 \mathrm{lb}$ axial load with $0.100 \mathrm{in}$. offset and also at lower axial load of $600 \mathrm{lb}$ with 0.175 in. offset. Yielding was evident both at ambient and cryogenic temperatures $\left(-320^{\circ} \mathrm{F}\right)$.

9.2 The tie rod performed satisfactorily when subjected to reactor environmental temperature $\left(-320^{\circ} \mathrm{F}\right)$ and maximum possible lateral displacement (0.20 in.). The tie rod was cycled at cryogenic temperature in the same plane for 25 cycles with offset varying between 0 and $0.067 \mathrm{in}$. and axial 


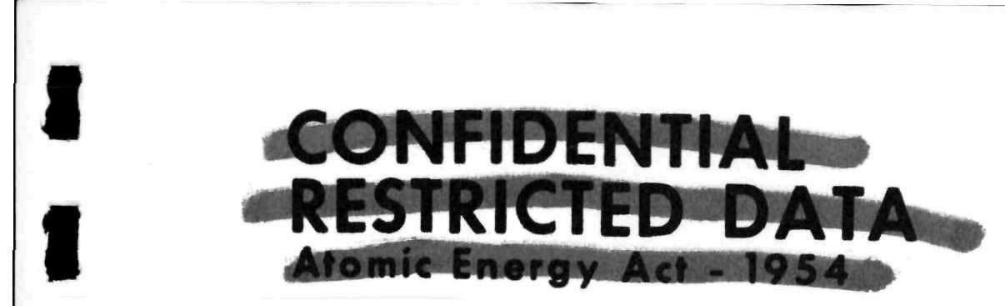

Lstronuclear

WANL-TME-823

load between $50 \mathrm{lb}$ and $820 \mathrm{lb}$; then again for 25 cycles each at 0 to $0.100 \mathrm{in.,} 0$ to $0.150 \mathrm{in.}$, and 0 to $0.200 \mathrm{in}$. offset with axial loads varying between $50 \mathrm{lb}$ and $820 \mathrm{lb}$. These load conditions resulted in a permanent set (bend) in the tie rod at the centering bushing due to yielding in the tie rod. Each cycle consisted of; (1) offset, (2) load axially, (3) unload, and (4) return offset to 0 .

9.3 The structural durability of the tie rod was found to be excellent with respect to long life under severe operating conditions. The tie rod was subsequently offset cycled at $-320^{\circ} \mathrm{F}$ for over 38,000 cycles with a constant maximum anticipated axial load of $820 \mathrm{lb}$ and offset varying from 0 to $0.200 \mathrm{in}$. before failure occurred. The rod fractured approximately $1 / 16 \mathrm{in}$. inside the split bushing where fretting was rather severe (Ref. Figure 11). The break occurred in an area where the measured strain was less than $1 / 3$ the strain at the thread end.

9.4 It was found that severe wear occurred between the tie rod and the pre-load spring during cycling at $0.200 \mathrm{in}$. offset due to moving contact between these parts. The wear on the tie rod, measuring about 6 to 10 mils of the diameter occurred at about the second coil of the preload spring (bolt end) as shown on Figures 11 and 12. Although this worn section of the tie rod was weakened due to the reduced cross section, failure did not occur because of the lower induced stresses at this point.

\section{TEST PROCEDURE}

10.1 Stresscoat to indicate direction and location of maximum stress point was applied to the tie rod as shown in Figure 9 before the rod was assembled in the test rig and installed in the Widemann Testing Machine. An axial load of $200 \mathrm{lb}$ and offset of $0.250 \mathrm{in}$. was imposed on the rod after which the rod was removed from the rig for observation 
of the crack (stress) pattern in the stresscoat.

10.2 The tie rod, instrumented as shown in Figure 6, was installed in the machine as shown in Figures 1 and 7. Various conditions of axial loads and offsets were applied to the rod at ambient temperature to determine strains under these conditions. Difficulties were at first encountered in routing of gage lead wires and it was necessary to modify the tie rod bolt (Figure 8 ) for passage of the lead wires. The strains determined from these tests are graphically illustrated in Figure 4. A plot of load and offset versus cumulative bending tensile strain in Figure 5 illustrates yielding effects due to overloading (loading beyond the elastic limit) of the rods.

10.3 Single plane cyclic testing at cryogenic temperature was accomplished by offsetting the rod, applying axial load, removing offset, and finally releasing the axial load. The tie rod was cycled (Figure 1) for 25 cycles each at $0.067 \mathrm{in}$. offset, $0.100 \mathrm{in}$. offset, $0.150 \mathrm{in}$. offset, and $0.200 \mathrm{in}$. offset, with a maximum axial load of $820 \mathrm{lb}$. The $820 \mathrm{lb}$ axial load was determined by first applying a $600 \mathrm{lb}$ axial load and then stretching the tie rod an additional $0.046 \mathrm{in}$. which represents additional elongation in the peripheral rod as a result of support plate deflection, friction and thermal growth.

10.4 Offset cycling was applied at cryogenic temperature $\left(-320^{\circ} \mathrm{F}\right)$ to determine the structural durability of the tie rod under the most severe operating conditions anticipated during reactor operation. A variable speed gear-motor rotated the fixture by means of a $\mathrm{V}$-belt drive as shown in Figure 10 at a speed of 260 revolutions per minute with the offset at $0.200 \mathrm{in}$. and a steady axial load of $820 \mathrm{lb}$. The wobbling action induced in the tie rod also approximately simulates a torsional displace- . ment of the core. 


\section{- "-}

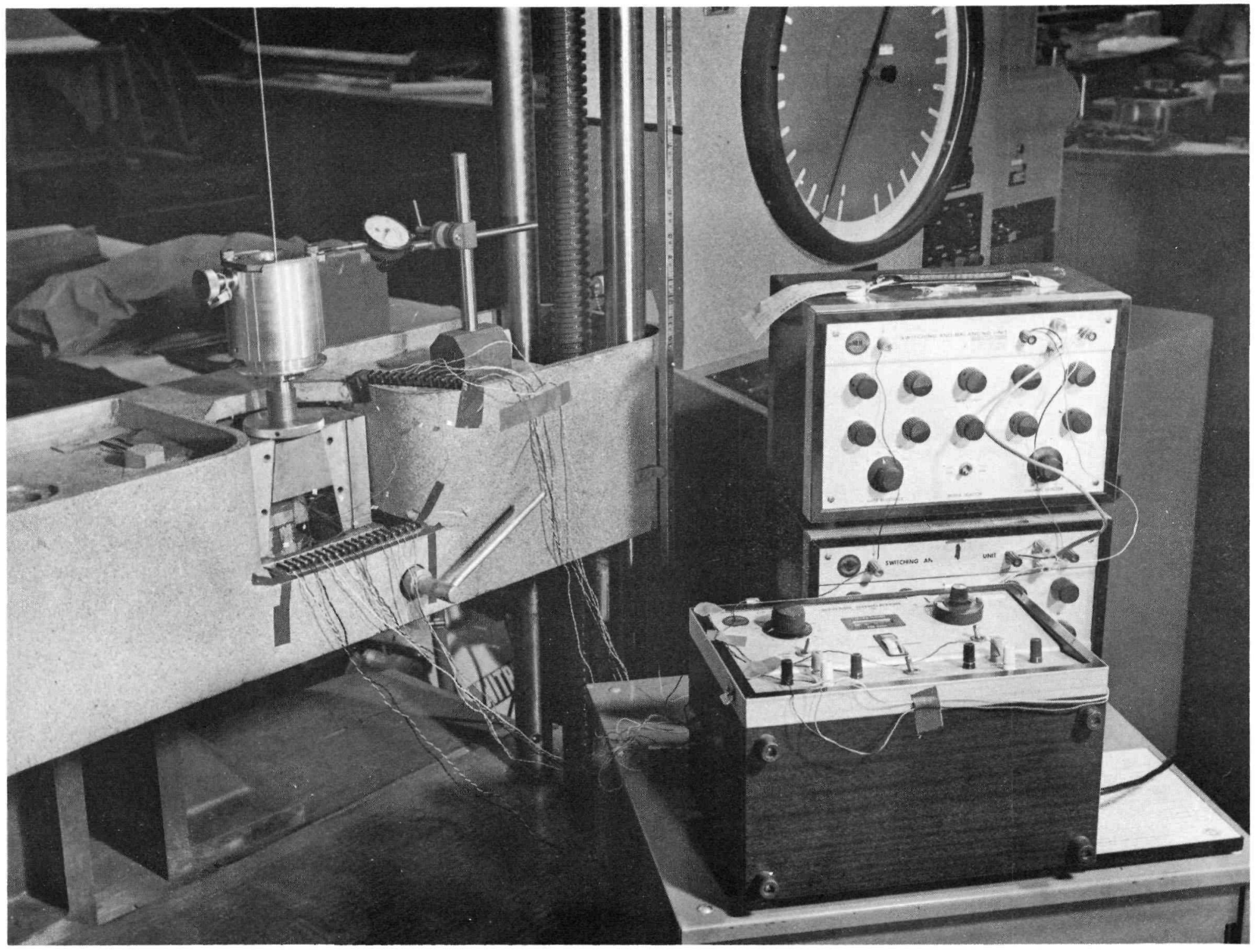

FIGURE 1 


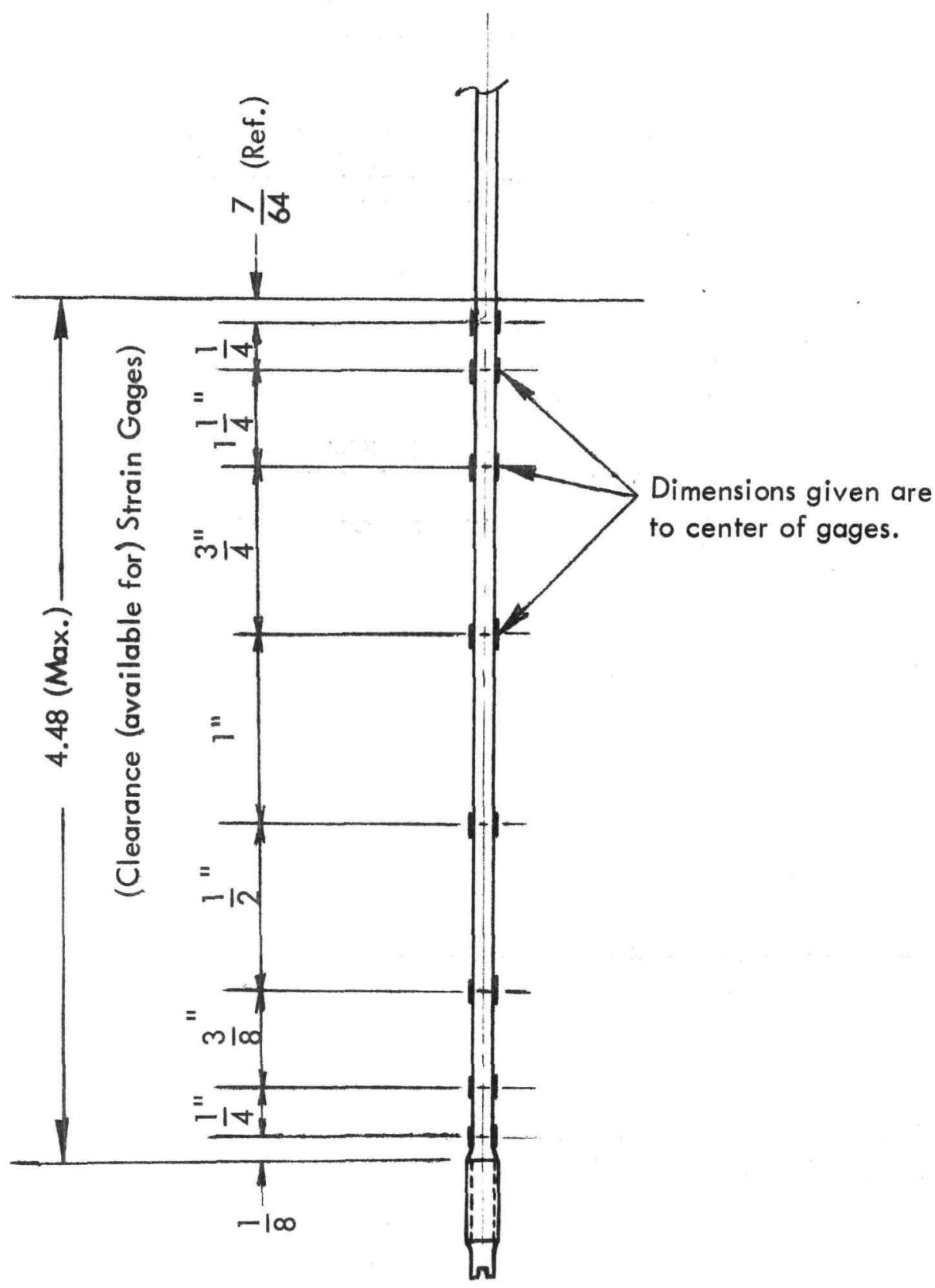

FIGURE 3

Strain Gage Locations 


\section{$m$}

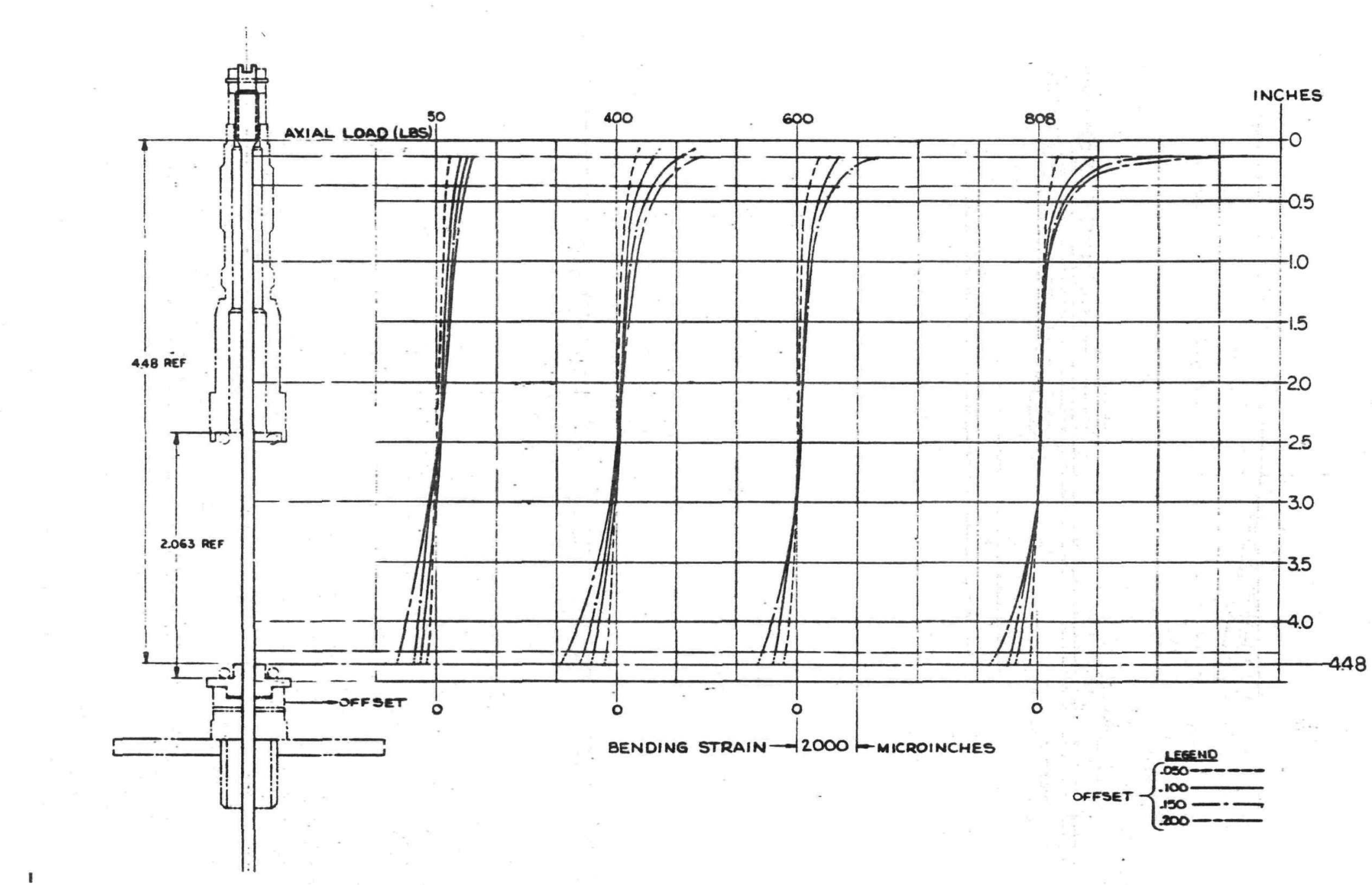

$\frac{1}{N}$

FIGURE 4

Strain Distribution Under Various Offset Conditions

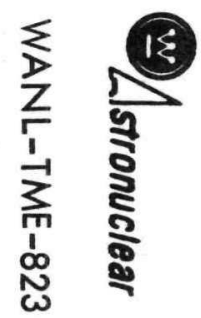




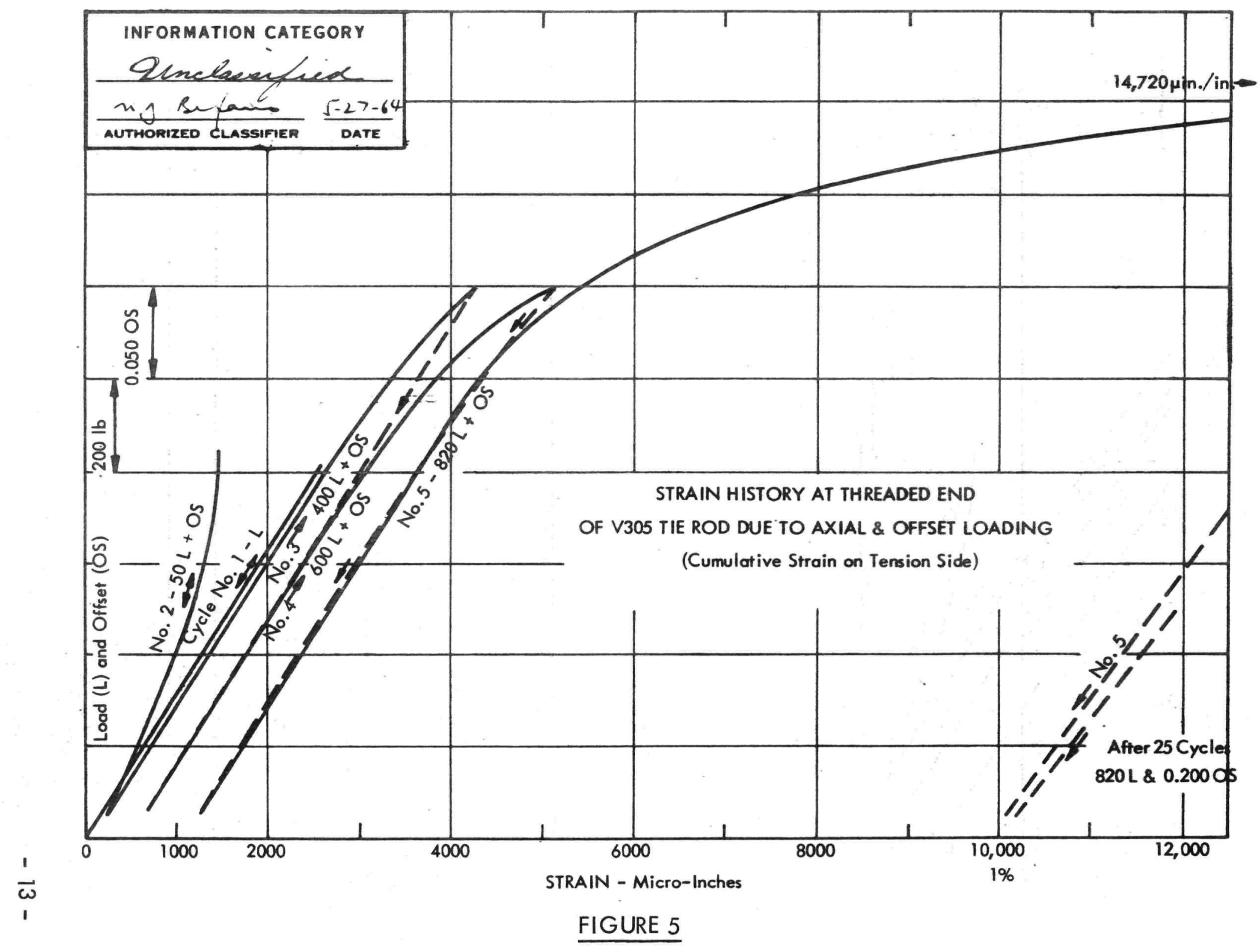

Strain History at Threaded End of Tie Rod

Due to Axial and Offset Loading 

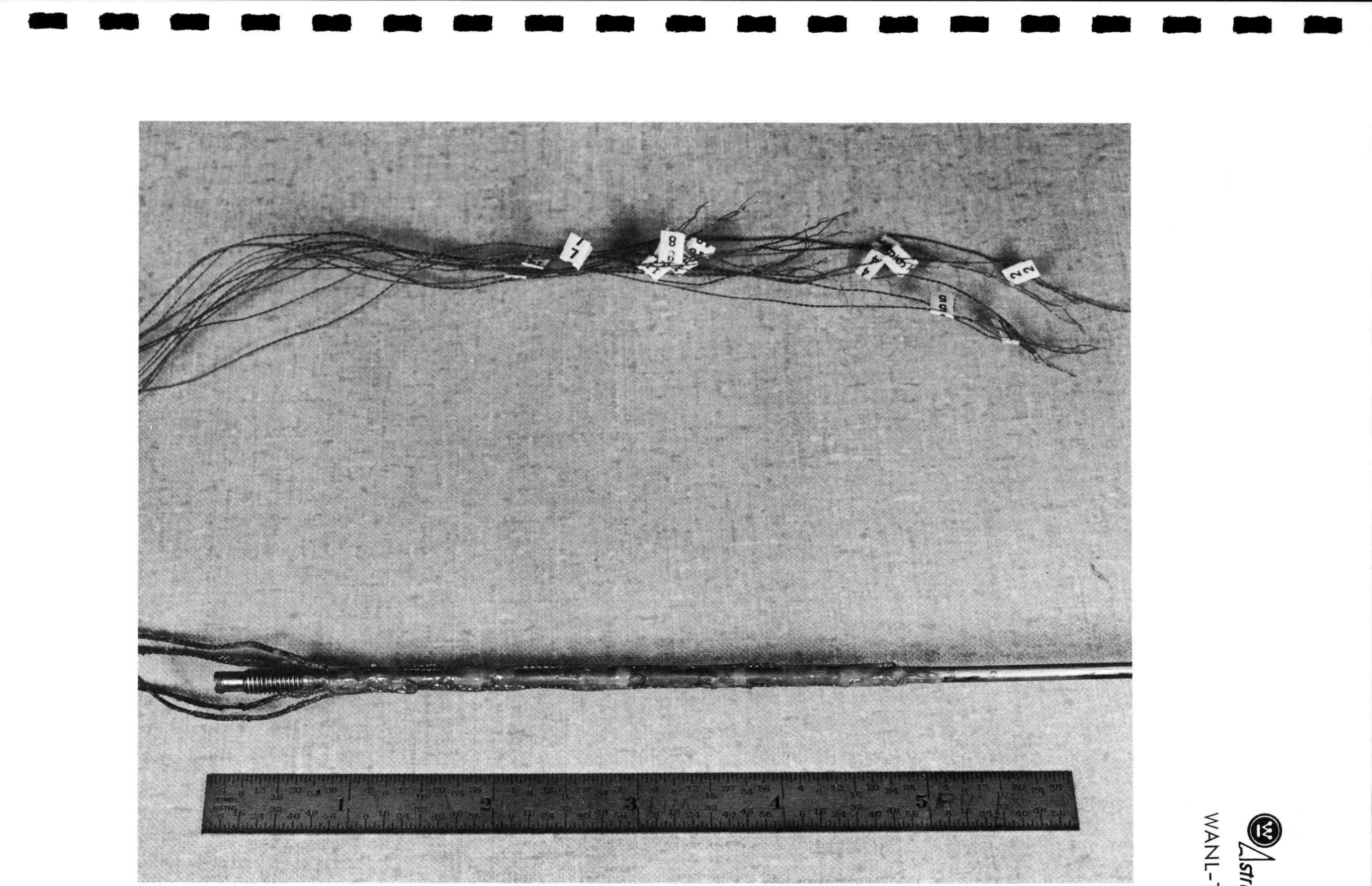

$\frac{1}{1}$

\section{FIGURE 6}

Showing Strain Gages on Tie Rod

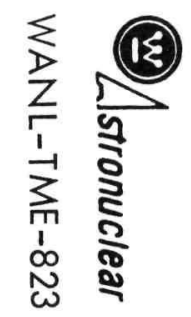




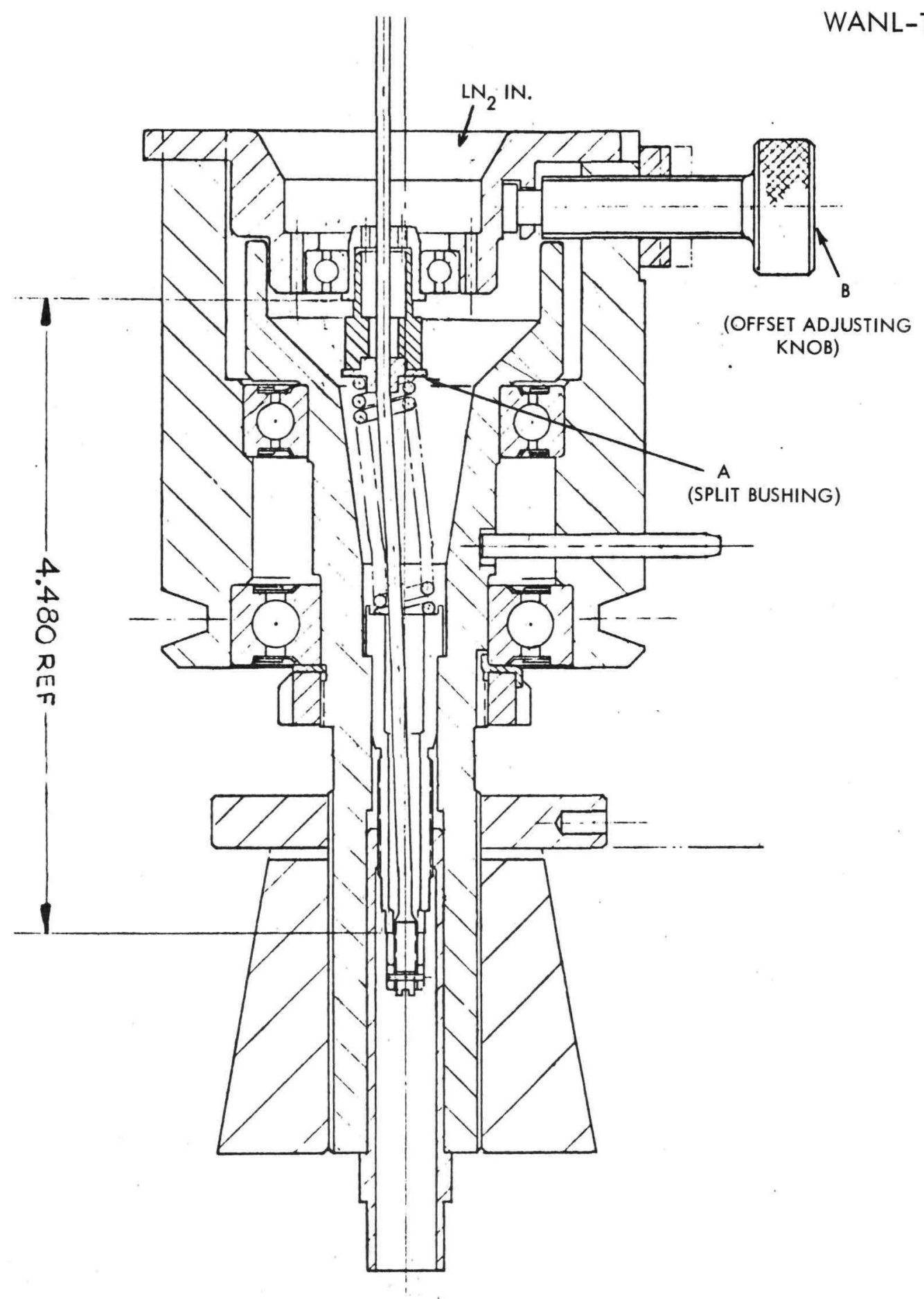

FIGURE 7

Cross Section of Tie Rod Offset Test Rig 


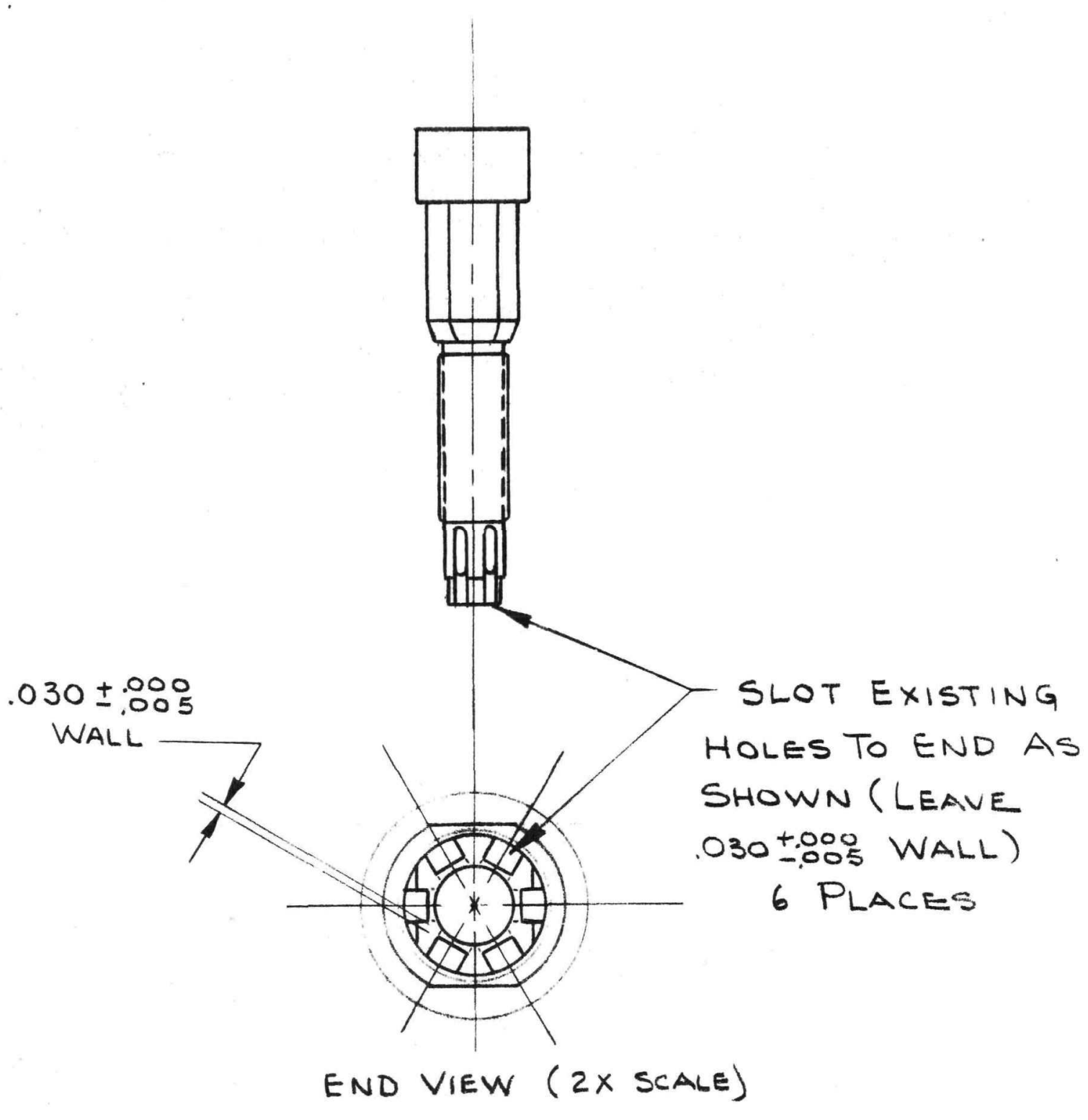

\section{FIGURE 8}

Modified Tie Rod Bolt 
WANL-TME-823

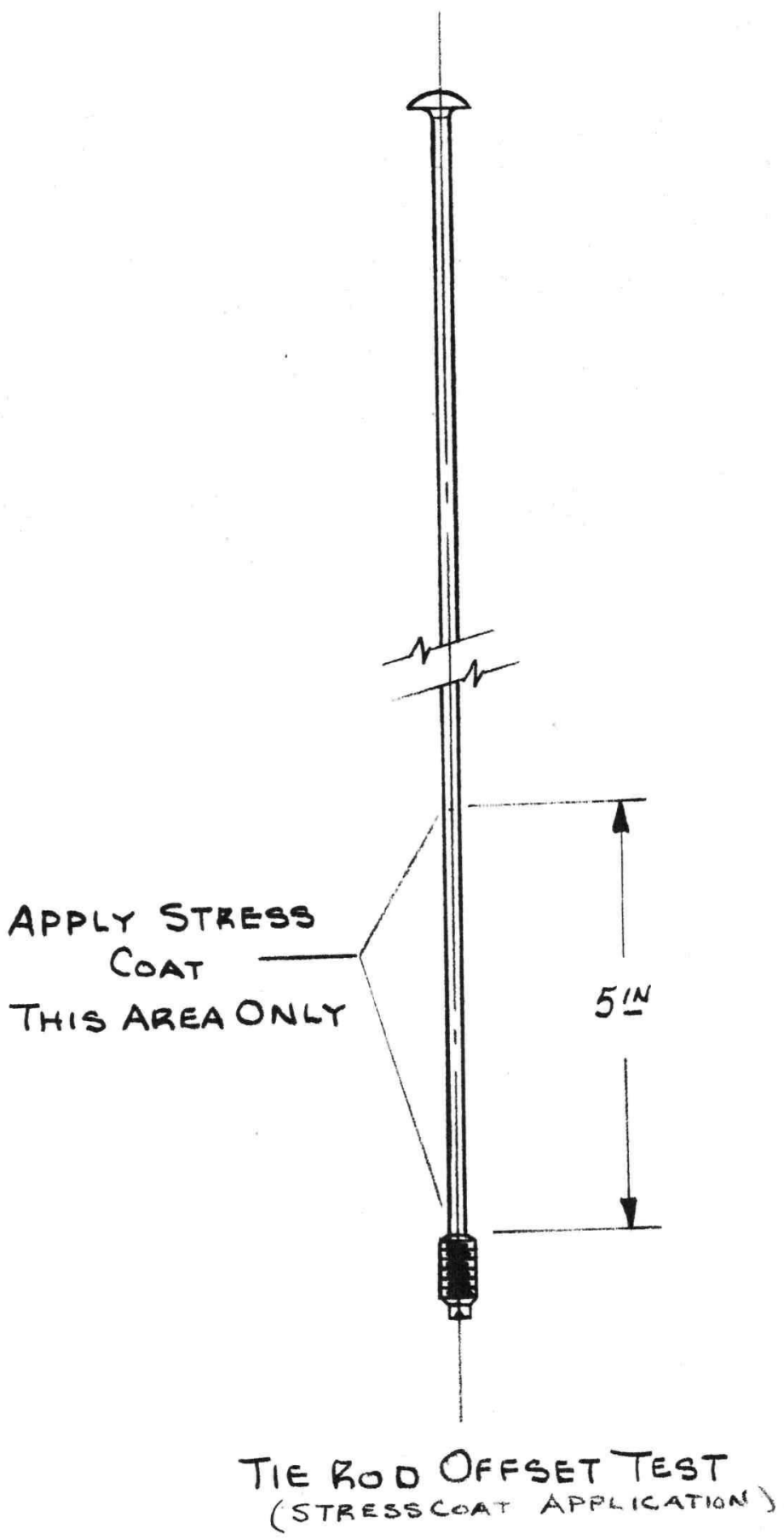

FIGURE 9

Stresscoated Tie Rod 


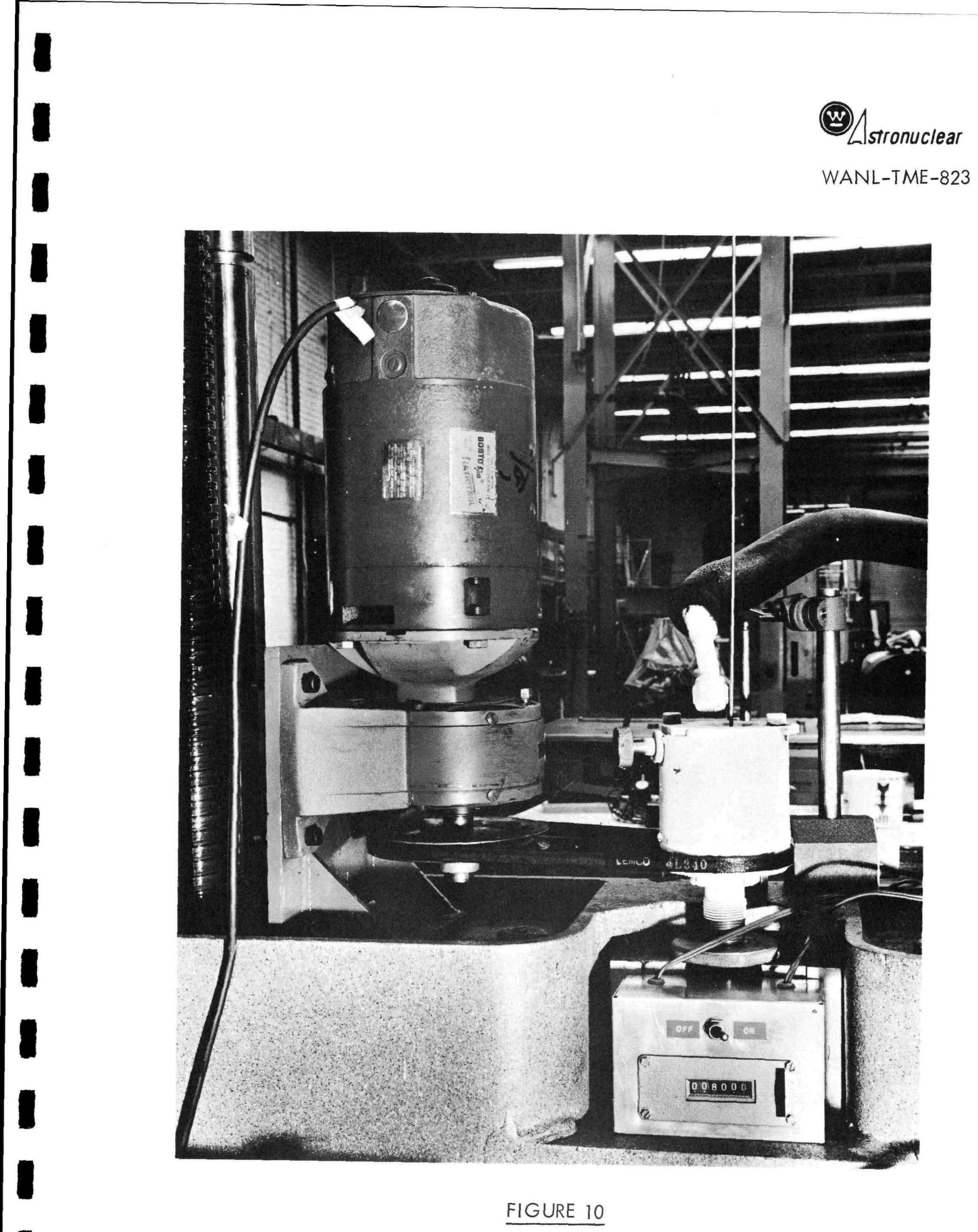

Variable Speed Drive for Torsional Bending 
(․) Stronuclear

WANL-TME-819

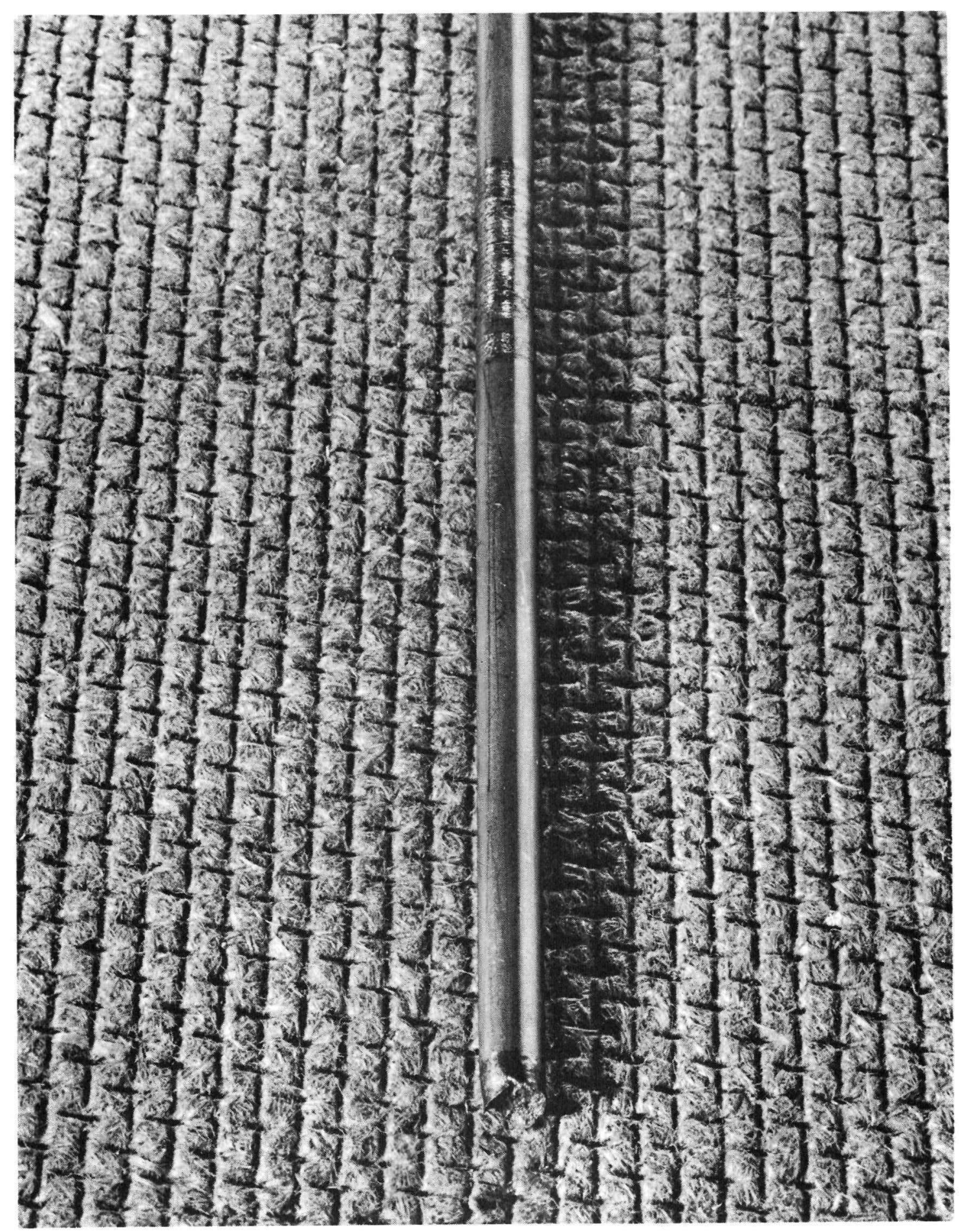

FIGURE 11

Tie Rod Fractured End Showing Fretting at Break 
(w) Stronuclear

WANL-TME-823

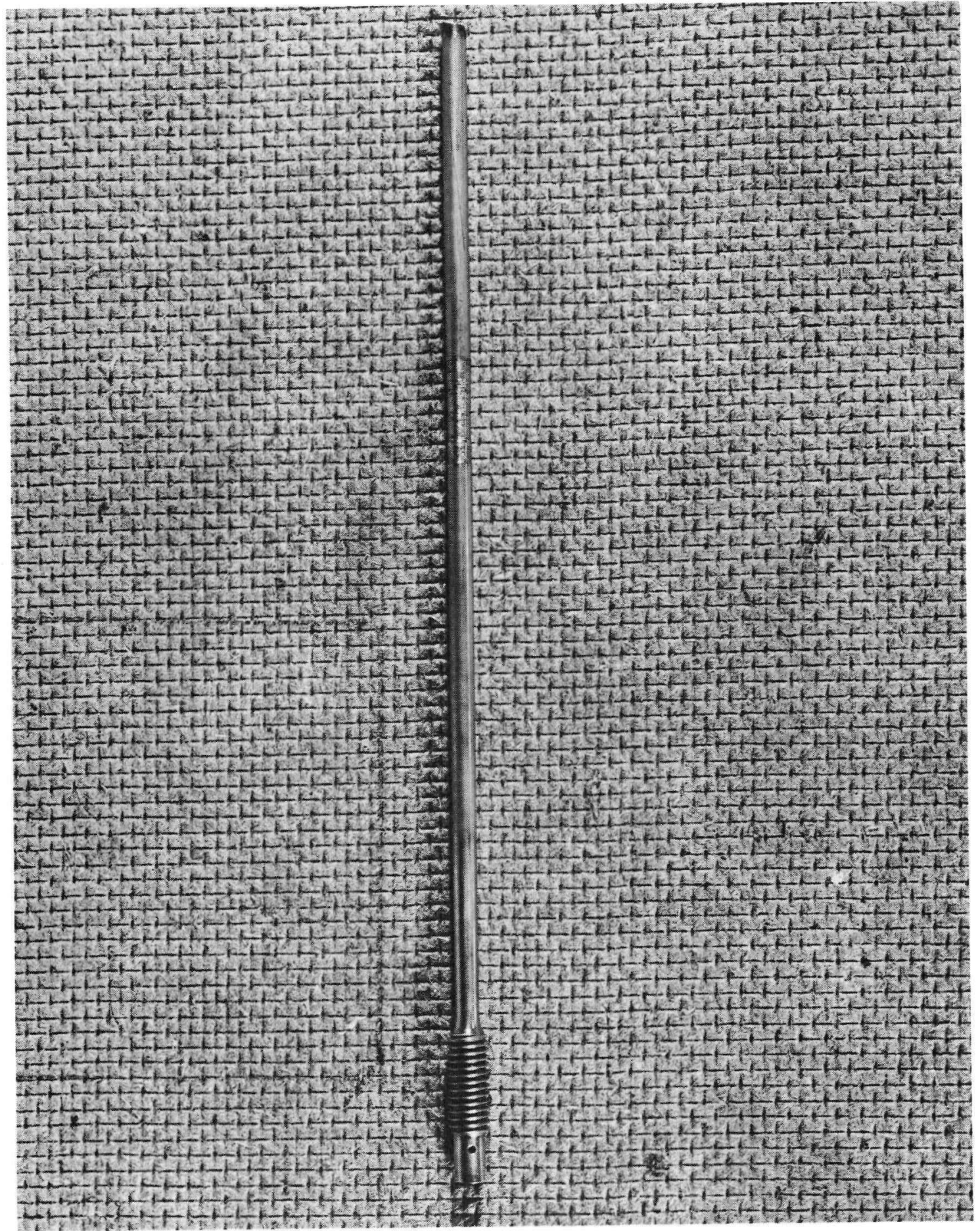

FIGURE 12

Fractured Tie Rod 